well written. It also contains that element that is so often missing from modern texts - the authors' own comments on experience. It reviews the history of ionexchange methods, discusses the synthesis of the materials and gives an excellent account of their physical and chemical properties as well as a good review of the plateequilibrium theory of the exchange mechanism.

I consider that this is the best book that has yet been produced on the subject of ion exchangers in analytical chemistry. It contains a wealth of theoretical background and practical information and gives all manner of useful hints on the preparation and use of columns, detection methods, and the like. It abounds in diagrams, graphs and tabular data and is as up to date as one could hope for in such a rapidly developing area.

T. S. WEST

\section{REACTIONS ON SURFACES}

\section{Catalysis by Nonmetals}

Rules for Catalysis Selection. By Oleg V. Krylov. Trans. lated by M. F. Delleo, jun., G. Dembinski, J. Happel, and A. H. Weiss. (Physical Chemistry: a Series of Monographs.) Pp. $x+283$. (Academic: New York and London, May 1970.) $131 s$.

THIs volume is devoted to heterogeneous catalysis excluding catalysis by metals, and is concerned most particularly with reactions occurring on oxide surfaces. The first part discusses the various properties of a solid, electronic (for example, conductivity, work function, band gap, doping, electronegativity difference, d-electron configuration, colour), acid-base, and geometric, which may serve as a basis for the characterization and selection of catalysts. The second part examines a number of practical catalytic reactions including elimination, hydro. genation, dehydrogenation, exchange, oxidation, isomerization, condensation, cracking, and polymerization. In each case a very determined effort is made to correlate published activity with the solid properties discussed earlier and to see which of these are the most significant for defining rules for the selection of catalysts.

The general approach reflects much recent Russian thinking on the empirical principles of catalysis, but the experimental material covered is not restricted to Russian work. The translation seems to have been a little mechanical and provides a quaint taste of the original; but as a result it needs to be read with some previous understanding of the subject matter. The book should be of considerable interest to all workers in heterogeneous catalysis.

C. S. G. Phillips

\section{USES FOR CARBON}

\section{Active Carbon}

Manufacture, Properties and Applications. By M. Sınisek and S. Cerny. (Topics in Inorganic and General Chemistry, Monograph No. 12.) Pp. xii + 479. (Elsevier: Amsterdam, London and New York, 1970.) 225s.

CURREnT publications, devoted entirely to carbon and graphite, make no serious reference to the manufacture and applications of active carbon. This book attempts to make good the omission by discussing the manufacture, properties, structure and applications of active carbons, methods of quality control together with the theory and dynamics of adsorption.

The appearance of the book is timely: carbons generally are emerging from the dark ages of empiricism to play an enlightened part in environmental control. Chemists, chemical and civil engineers will find here collected material of immediate practical interest and of reference value. It is hoped that the book will stimulate an informed demand for quality control of specific active carbons. Some thirty applications are discussed including solvent recovery, deodorization of air and water, and sugar purification. Industrial manufacturers are developing hard active carbons capable of extensive re-cycling with low abrasion characteristics. The production of specific active carbons requires, at least, control of pore-size and surface functional groups with reliable, realistic means for characterization. 'The Czech authors have? seriously attempted to present theories of adsorption from vapour and liquid states and of pore characterization in terms of carbonaceous systems. The Dubinin theory of adsorption is clearly explained and it is gratifying to read (p. 116), what $I$ have suspected for some time, that this theory is based on an inspired guess. But I must mildly caution readers of the more theoretical sections. These are translations from an earlier book (1964) upgraded by more recent references, but their contents are often not integrated into the text. Hence, a few outdated ideas of a decade ago are perpetuated: comparisons between active carbons and graphite are not realistic (p. 47); the graphite crystallite is only a crystallographic myth (p. 50); the basic concepts of Franklin are now justifiably disputed (p. j5); we have no unequivocal evidence for stating that selective gasification of distinct structural components creates pores (pp. 12 and 55).

HaRRY MARSh

\section{SOVIET NEWS}

\section{Soviet Science Review}

Scientific Developments in the USSR. Vol. 1, No. 1. Bimonthly. Pp. 56. (Iliffe (Science and Technology): Guildford, July 1970.) Annual subscription 300s; $\$ 37.50$.

It is difficult to judge a new journal from its first issue, particularly when the subject covered is as wide-ranging as the whole field of Soviet science. A general impression is all that can be gained, and this impression, in the case of Soviet Science Review, is a somewhat diappointing one.

The subjects covered range from space medicine to ichthyology and from hypnosis to pollution, but the general effect is that of "prestige" achievements written up for publicity purposes, rather than a serious appraisal of current research. There are some rather extravagant claims and certain inconsistencies, as in the paper on vitreous semiconductors, where the text reads "The experimental research situation is well symbolized in Fig. 1. Point A shows that for some time after the discovery of this new class of glasses, our Institute was the only research body that studied them", whereas in fact (and according to the caption) Fig. 1 represents the possible alloys of metal oxides, sulphides, selenides and tellurides of vitreous and non-vitreous composition, and point $\mathrm{A}$ corresponds to an alloy of $\mathrm{Tl}_{2} \mathrm{Se}$ and $\mathrm{As}_{2} \mathrm{Se}_{3}$.

The bibliographies to the individual papers might well have been composed in the pre-thaw days when scientific isolation was standard Soviet policy. Apart from two references on water pollution, all the works cited are of Soviet provenance, so that it is almost impossible to relate the papers to parallel research in other countries. Another serious defect of the bibliographies is the retitling of Russian works in English (except in the case of the paper on ichthyology) which might well lead to difficulties in tracing the original Russian papers which are the primary source of this material.

Soviet Science Review is published by Iliffe in cooperation with the Academy of Sciences of the USSR. It has an impressive editorial board of Soviet academicians, but the general tone of the publication speaks rather of the Novosti news agency (another associated body) than of the academy. 